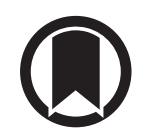

CrossMark

\title{
Urging Europe to put non-adherence to inhaled respiratory medication higher on the policy agenda: a report from the First European Congress on Adherence to Therapy
}

\author{
Job F.M. van Boven ${ }^{1,2}$, Federico Lavorini ${ }^{3}$, P.N. Richard Dekhuijzen ${ }^{4}$, \\ Francesco Blasi ${ }^{5}$, David B. Price ${ }^{6,7}$ and Giovanni Viegi, $i^{8,9}$
}

\begin{abstract}
Affiliations: ${ }^{1}$ Dept of General Practice, Groningen Research Institute for Asthma and COPD (GRIAC), University Medical Center Groningen, University of Groningen, Groningen, The Netherlands. ${ }^{2}$ Dept of Clinical Pharmacy \& Pharmacology, University Medical Center Groningen, University of Groningen, Groningen, The Netherlands. ${ }^{3}$ Dept of Experimental and Clinical Medicine, University of Florence, Florence, Italy. ${ }^{4}$ Dept of Pulmonary Diseases, Radboud University Medical Center, Nijmegen, the Netherlands. ${ }^{5}$ Dept of Pathophysiology and Transplantation, University of Milan, Cardio-thoracic Unit and Adult Cystic Fibrosis Center, Fondazione IRCCS Cà Granda Ospedale Maggiore Policlinico, Milan, Italy. ${ }^{6}$ Academic Primary Care, University of Aberdeen, Aberdeen, UK. ${ }^{7}$ Observational and Pragmatic Research Institute, Singapore. ${ }^{8}$ Pulmonary Environmental Epidemiology Unit, CNR Institute of Clinical Physiology, Pisa, Italy. ${ }^{9} \mathrm{CNR}$ Institute of Biomedicine and Molecular Immunology, Palermo, Italy.
\end{abstract}

Correspondence: Job F.M. van Boven, Dept of General Practice, Groningen Research Institute for Asthma and COPD (GRIAC), University Medical Center Groningen, University of Groningen, Antonius Deusinglaan 1, 9713 AV Groningen, The Netherlands. E-mail: j.f.m.van.bovenarug.nl

\section{@ERSpublications}

Huge impact, but little attention: time to put respiratory non-adherence higher on Europe's policy agenda! http://ow.ly/vVDj309Yblz

Cite this article as: van Boven JFM, Lavorini F, Dekhuijzen PNR, et al. Urging Europe to put nonadherence to inhaled respiratory medication higher on the policy agenda: a report from the First European Congress on Adherence to Therapy. Eur Respir J 2017; 49: 1700076 [https://doi.org/10.1183/ 13993003.00076-2017].

\begin{abstract}
Introduction
"Drugs don't work in patients that don't take them" are the by now almost legendary words of former US Surgeon General C. Everett Koop. Arguably worse than "just not working", for the European Union (EU), it has been estimated that non-adherence to medication is associated with almost 200000 deaths and an excess cost of EUR80-125 billion [1]. Realising that 1) non-adherence affects about $50 \%$ of chronic medication users [2], of which the large majority elderly, and 2) tackling non-adherence requires a joint effort, the Senior International Health Association took the initiative to bring together seniors, clinical and adherence experts, and European Parliament members. On November 18 and 19, 2016, all these key stakeholders met at the First European Congress on Adherence to Therapy in Rimini, Italy, passionately chaired by Giovanni La Via, President of the Environment, Public Health and Food Safety Committee of the European Parliament. Notably, there were representatives from several major European scientific societies, i.e. those of pulmonology (ERS), atherosclerosis (EAS), urology (EAU), heart rhythm (EHRA), psychiatry (EPA), cardiology (ESC) and hypertension (ESH). The overall goal of the congress was to
\end{abstract}

Received: Jan 132017 | Accepted after revision: Jan 252017

Conflict of interest: Disclosures can be found alongside this article at erj.ersjournals.com

Copyright OERS 2017 
identify unmet needs in adherence research, funding and policy by specifying the roles of patients, healthcare providers, societies, funding bodies and governments. In this report, we present the main conclusions and recommendations following the congress, in particular those of interest for healthcare policy regarding inhaled medication non-adherence in patients with obstructive airway diseases (i.e. asthma and/or chronic obstructive pulmonary disease (COPD)).

\section{Clinical and economic impact of non-adherence to inhaled respiratory medication}

For most chronic oral medications, prescribers' recommendations usually indicate taking the correct dose at the right time of day. A complicating factor for inhaled respiratory medication is that the correct way of administration (i.e. proper inhaler handling and technique) is also of paramount importance, resulting in even lower real-world adherence rates compared to other chronic medications [3]. Despite continuous inhaler redesign and refinement [4], incorrect inhalation handling and techniques persist [5], resulting in suboptimal medication implementation and compromised asthma and COPD treatment outcomes [6]. The large number of inhalers currently available, as well as insurance policy-driven inhaler switching, may worsen these outcomes even more [7]. Furthermore, the use of multiple inhaler devices by an individual patient has been shown to be associated with a higher prevalence of errors than the use of single devices [8].

Exact inhaled respiratory medication adherence rates vary depending on the definition used, but are known to be lower in adolescents and certain other groups, such as those with lower socioeconomic status [9]. Non-adherence to inhaled medication, including inappropriate inhaler use, is associated with a higher mortality, increased number of exacerbations, hospitalisations and emergency department visits, as well as increased economic burden [10-13]. Obviously, both on the clinical and economic level, there is much to gain by focusing on solutions to enhance medication adherence in patients with obstructive airway diseases. In the EU, 600000 people die each year because of respiratory diseases, up to one-fifth of the population aged 5-80 years will develop asthma, and prevalence and burden continue to rise [14].

Now that most of the background and consequences of non-adherence to inhaled medication are known, it seems time to really make some changes and, in our view, optimal implementation of adherence-enhancing interventions is currently the key. However, this requires a coordinated approach and adequate funding. The EU seems well equipped to fulfil this role. The question arises: what role has the EU played so far and what role should it play?

\section{EU-funded projects related to adherence to inhaled respiratory medication}

To enable adherence research, the availability of sufficient resources is a first prerequisite. Second, given the causes of non-adherence are multifactorial and complex [15], research could benefit from international, multidisciplinary and private-public collaboration. The EU could therefore play a key role in coordinating adherence research. Indeed, within the 7th Framework Programme (FP7) and Horizon 2020 frameworks, the EU has the possibility to stimulate collaborative research across Europe. In recent years, one of the most prominent adherence projects funded by the EU was the Ascertain Barriers for Compliance (ABC) project. This project has led to general, disease-neutral adherence recommendations at the policy, healthcare professional, patient and government level [16]. Within the ABC project, a new taxonomy to define adherence phases was established, now distinguishing between initiation, implementation and persistence [17]. In a later follow-up study focusing on respiratory medicine, special attention was paid to inhaler technique as an important part of the implementation phase [18]. Currently, two other EU-FP7-funded projects target some respiratory non-adherence issues, in particular related to asthma treatment. These are the EARIP and the ASTRO-LAB projects. EARIP aims to identify areas that scientists and funders should focus on regarding the optimisation of asthma treatment, including non-adherence issues [19]. ASTRO-LAB focuses on the use of long-acting $\beta$-agonists in asthma and also addresses adherence factors influencing pulmonary drugs' effectiveness [20, 21]. However, none of these EU projects has a key focus on inhaler misuse and adherence-enhancing solutions, especially not in patients with COPD.

For the period 2014-2020, almost EUR75 billion is available [22] and more than 11000 signed projects are currently funded through the EU Horizon 2020 programme [23]. About 30 grants have the word "adherence" in their primary project objective, of which only one focuses on adherence in asthma patients (ASTHMAPOC) and one on cystic fibrosis (MyCyFAPP). The number of large international projects focusing on non-adherence in general and in respiratory medicine seems, however, to fall short compared to the considerable clinical and economic impact of the issue. Back in 2005, a systematic review on adherence-enhancing interventions already noted that "improving adherence seems to be fairly low on the policy agenda, but better use of existing technologies (e.g. drug therapy) is likely to be more cost-effective than many new technologies", later confirmed for COPD [24, 25]. Nevertheless, subsequent epidemiological studies on respiratory medication adherence continued to indicate consistently low adherence, and a very recent study 
also showed hardly any improvements in inhaler technique over the last 30 years $[4,5]$, illustrating the need for better implementation strategies focusing on proper inhaled respiratory medication use.

\section{Various solutions to tackle non-adherence in obstructive airway diseases}

When designing and implementing interventions to tackle non-adherence in obstructive airway diseases, it is of utmost importance that one takes into account the multifactorial causes of non-adherence and tailor solutions accordingly. Much groundwork has already been performed, and we have now arrived at a stage where most of the underlying mechanisms, "phenotypes of non-adherence" and targets have been uncovered. The 2003 World Health Organization adherence report distinguished between erratic non-adherence (forgetfulness), intelligent non-adherence (conscious decision not to take medication due to side-effects or lack of beliefs, for example) and unwitting non-adherence (lack of knowledge) [2]. Given these different "phenotypes" (which can occur alongside each other), one-size-fits-all solutions are very likely to fail, and interventions should clearly be tailored to the specific needs and beliefs of each individual patient [26-28]. However, it is not only the patient that could be targeted when aiming to optimise adherence. Non-adherence modifiers at the patient, system and treatment level [11] could all play a role and are often the underlying cause of different types of non-adherence in one or more phases of the medication adherence process (figure 1). For adherence-enhancing interventions to work, healthcare providers must first make sure that they reaffirm the asthma/COPD diagnosis, treat comorbidities and urge patients to avoid triggers. Subsequently, it is necessary to 1) identify the phenotype of non-adherence and 2) find a tailored solution that fits the type of non-adherence and targets its underlying cause(s) appropriately. At the First European Congress on Adherence to Therapy, several potential solutions were identified and discussed, and these are summarised in figure 1. Most interventions have been described in the literature and are ready to be implemented in real-world practice, especially as some newly developed objective electronic adherence measurement techniques are becoming available $[29,30]$.

\section{Key points from the First European Congress on Adherence to Therapy}

During the First European Congress on Adherence to Therapy, lectures from European policy-makers, interactive public sessions and clinically oriented round-table discussions have resulted in a set of key recommendations to address the non-adherence issue within the EU. A general manifest was created in which adherence was positioned as a right for every patient and as an issue that requires increased awareness from all stakeholders involved [31]. In addition, issues of particular interest for the respective chronic disease areas represented were identified. In table 1 a summary of these general as well as respiratory-specific

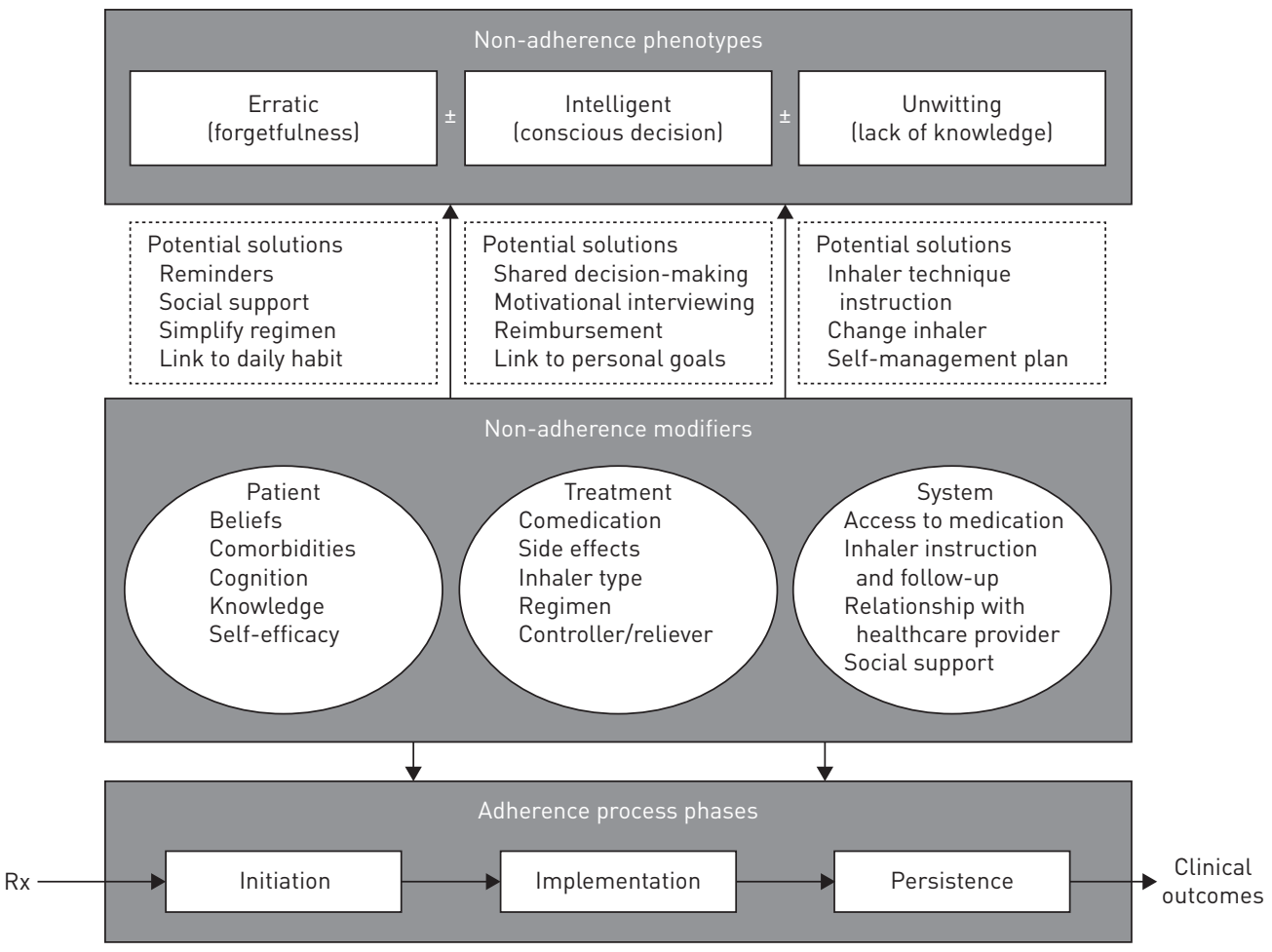

FIGURE 1 Targets for interventions to optimise adherence to inhaled respiratory medications. Rx: prescription. 
TABLE 1 Key points from the First European Congress on Adherence to Therapy

\section{Summary of the European Charter on Adherence to Treatment}

1) Adherence to treatment as a right for chronic patients: patients deserve optimal education, but at the same time their best self-effort is required

2) Patient education and, where necessary, of the caregivers, to implement adherence to treatment: patients should be appropriately informed on the importance of adherence, the clinical and economic consequences of non-adherence and should receive the necessary tools to remain adherent

3) Awareness of families and family caregivers: caregivers can play a key role in ensuring optimal implementation and monitoring of therapy (e.g. awareness of side-effects or running out of medication) at home

4) Awareness of general medicine: the primary contact point and coordinator of care for the elderly multimorbid patient. The general practitioner should take care of promoting adherence by optimal communication skills and up-to-date knowledge of monitoring and educational tools that can assist in addressing non-adherence

5) Awareness of scientific societies and medical specialists: societies should mark adherence as an essential step in their guidelines

6) Awareness of nurses: nurses should establish a strategic partnership with prescribers. Nurse organisations should address adherence in their educational curriculum

7) Awareness of pharmacists: they are a cornerstone for therapy adherence and monitoring especially in the elderly with polypharmacy. They are the first referral point when drug non-adherence is signalled

8) Awareness of drugs manufacturers: they should focus on simplifying devices, combinations of drugs, dosing regimens and packages

9) Awareness of institutions: should prepare for the shift from acute care to chronic care models

10) European institutions: should finance programme to optimise adherence and stimulate other parties such as industry and national governments

\section{Additional issues of interest to address inhaled respiratory medication non-adherence}

Patient

Priority patient groups for interventions: non-adherent patients with lower socioeconomic status, patients with uncontrolled obstructive airway disease, more severe patients and patients with polypharmacy

Treatment

Prerequisites before improving adherence: reaffirm asthma/COPD diagnosis, treat comorbidities and avoid triggers

Tailor the inhaler, regimen and adherence-enhancing interventions to the needs and beliefs of the patient

Promote uniformity of inhaler and avoid switching without reason

Consider electronic adherence monitoring: especially those devices that combine timing of use, quality of use and continuity of use System

Enhancing adherence in patients with asthma/COPD is needed and is cost-effective

Invest in well-trained professionals, provide sufficient time and reimbursement for educational adherence-enhancing interventions, including inhaler technique training

To tackle non-adherence, a multidisciplinary approach is needed: physicians, pharmacists and nurses should all have excellent communication and educational skills and, locally, a coordinated approach is needed

Funders should provide sufficient funding for well-designed implementation studies on successful adherence-enhancing strategies in asthma/COPD patients

Uniform inhaler instructions should be promoted nationally

COPD: chronic obstructive pulmonary disease.

recommendations is provided. Both aspects may be of interest for future European funding calls and policy-making.

\section{Conclusions}

Despite the considerable clinical and economic burden of non-adherence, strategies to improve adherence in obstructive airway diseases have received too little attention. Taking into account the ageing European population, the increasing number of asthma/COPD patients and the wealth of new inhalers available, it is time to put non-adherence to inhaled respiratory medication higher on the policy agenda of European and national funding bodies.

\section{Acknowledgements}

The authors thank Stefano Nardini (Pulmonary and TB Unit, Vittorio Veneto General Hospital, Vittorio Veneto, Italy) for moderating the respiratory session and all discussants for their input. A full report from the First European Congress on Adherence to Therapy is available (www.seniorinternationalhealthassociation.org/events/european-congress-on-adherenceto-therapy/). The views and opinions expressed here are those of the authors only.

\section{References}

1 European Commission/MEDI-VOICE. MEDI-VOICE Report Summary. Project ID: 17893. European Union/ European Commission, 2011.

2 World Health Organization. Adherence to Long-Term Therapies: Evidence for Action. Geneva, World Health Organization, 2003. Available from: http://apps.who.int/medicinedocs/pdf/s4883e/s4883e.pdf 
3 Priest JL, Cantrell CR, Fincham J, et al. Quality of care associated with common chronic diseases in a 9-state Medicaid population utilizing claims data: an evaluation of medication and health care use and costs. Popul Health Manag 2011; 14: 43-54.

4 Lavorini F, Fontana GA, Usmani OS. New inhaler devices - the good, the bad and the ugly. Respiration 2014; 88: 3-15.

5 Sanchis J, Gich I, Pedersen S, et al. Systematic review of errors in inhaler use: has patient technique improved over time? Chest 2016; 150: 394-406.

6 Makela MJ, Backer V, Hedegaard M, et al. Adherence to inhaled therapies, health outcomes and costs in patients with asthma and COPD. Respir Med 2013; 107: 1481-1490.

7 Braido F, Lavorini F, Blasi F, et al. Switching treatments in COPD: implications for costs and treatment adherence. Int J Chron Obstruct Pulmon Dis 2015; 10: 2601-2608.

8 Bosnic-Anticevich S, Chrystyn H, Costello RW, et al. The use of multiple respiratory inhalers requiring different inhalation techniques has an adverse effect on COPD outcomes. Int J Chron Obstruct Pulmon Dis 2016; 12: 59-71.

9 Tottenborg SS, Lange P, Johnsen SP, et al. Socioeconomic inequalities in adherence to inhaled maintenance medications and clinical prognosis of COPD. Respir Med 2016; 119: 160-167.

10 Williams LK, Peterson EL, Wells K, et al. Quantifying the proportion of severe asthma exacerbations attributable to inhaled corticosteroid nonadherence. J Allergy Clin Immunol 2011; 128: 1185-1191o.e2.

11 Vestbo J, Anderson JA, Calverley PM, et al. Adherence to inhaled therapy, mortality and hospital admission in COPD. Thorax 2009; 64: 939-943.

12 Melani AS, Bonavia M, Cilenti V, et al. Inhaler mishandling remains common in real life and is associated with reduced disease control. Respir Med 2011; 105: 930-938.

13 van Boven JF, Chavannes NH, van der Molen T, et al. Clinical and economic impact of non-adherence in COPD: a systematic review. Respir Med 2014; 108: 103-113.

14 Gibson JG, Loddenkemper R, Sibille Y, et al., eds. The European Lung White Book. Sheffield, European Respiratory Society, 2013.

15 Lareau SC, Yawn BP. Improving adherence with inhaler therapy in COPD. Int J Chron Obstruct Pulmon Dis 2010; 5: 401-406.

16 The ABC Project. Ascertaining Barriers for Compliance: Policies for Safe, Effective and Cost-effective Use of Medicines in Europe. Final Report of the ABC Project. Project ID: 223477. Lodz, ABC Project, 2012. Available from http://abcproject.eu/img/ABC\%20Final.pdf

17 Vrijens B, De Geest S, Hughes DA, et al. A new taxonomy for describing and defining adherence to medications. Br J Clin Pharmacol 2012; 73: 691-705.

18 Vrijens B, Dima AL, Van Ganse E, et al. What we mean when we talk about adherence in respiratory medicine. J Allergy Clin Immunol Pract 2016; 4: 802-812.

19 European Commission/EARIP. EARIP Project Summary. Project ID: 602077. European Union/European Commission, 2016.

20 European Commission/ASTRO-LAB. ASTRO-LAB project summary. Project ID: 282593. European Union/ European Commission, 2014.

21 Dima AL, Hernandez G, Cunillera O, et al. Asthma inhaler adherence determinants in adults: systematic review of observational data. Eur Respir J 2015; 45: 994-1018

22 European Parliament: Horizon 2020 Budget and Implementation. European Union/European Parliament, 2015. Available from: www.europarl.europa.eu/RegData/etudes/IDAN/2015/571312/EPRS_IDA(2015)571312_EN.pdf

23 CORDIS/European Union. EU Research Projects under Horizon 202 (2014-2010). https://data.europa.eu/euodp/ en/data/dataset/cordisH2020projects Date last accessed: December 30, 2016.

24 Elliott RA, Barber N, Horne R. Cost-effectiveness of adherence-enhancing interventions: a quality assessment of the evidence. Ann Pharmacother 2005; 39: 508-515.

25 van Boven JF, Tommelein E, Boussery K, et al. Improving inhaler adherence in patients with chronic obstructive pulmonary disease: a cost-effectiveness analysis. Respir Res 2014; 15: 66.

26 Dekhuijzen PN, Vincken W, Virchow JC, et al. Prescription of inhalers in asthma and COPD: towards a rational, rapid and effective approach. Respir Med 2013; 107: 1817-1821.

27 Blasi F, Bettoncelli G, Canonica GW, et al. The management of asthma in the phenotype and biomarker era: the proposal of a new diagnostic-therapeutic model. J Asthma 2016; 53: 665-667.

28 Dekhuijzen PN, Bjermer L, Lavorini F, et al. Guidance on handheld inhalers in asthma and COPD guidelines. Respir Med 2014; 108: 694-700.

29 van Boven JF, Trappenburg JC, van der Molen T, et al. Towards tailored and targeted adherence assessment to optimise asthma management. NPJ Prim Care Respir Med 2015; 25: 15046.

30 Sulaiman I, Cushen B, Greene G, et al. Objective assessment of adherence to inhalers by COPD patients. Am J Respir Crit Care Med 2016; in press [https://doi.org/10.1164/rccm.201604-0733OC].

31 Senior International Health Association. Press release 19 November 2016. http://siha.cloud.agoramed.it/ wp-content/uploads/2016/11/Press-release-SIHA-19-November1.pdf Date last accessed: December 30, 2016 